\title{
INVESTIGATION OF THE MECHANICAL, CORROSION PROPERTIES AND WEAR BEHAVIOUR OF ELECTROLESS Ni-P PLATED MILD STEEL
}

\author{
S. Ilangovan \\ Assistant Professor, Department of Mechanical Engineering, Amrita School of Engineering, Amrita Vishwa \\ Vidyapeetham, Coimbatore - 641105, Tamil Nadu, India.
}

\begin{abstract}
In the present study the mild steel (MS) specimens were coated with Nickel-Phosphorus (Ni-P) using acrylic bath. Heat treatment was carried out on specimens under different temperatures and time periods in an inert atmosphere. The various mechanical and tribological tests were performed on specimens. Using weight loss method, the corrosion nature of the samples under different environments was also studied. The results show that there was significant effect in mechanical and chemical properties of the plated specimens. The properties of the heat treated specimens increased significantly with modest loss in fatigue properties.
\end{abstract}

Keywords: Ni-P, surface coating, coefficient of friction, wear, corrosion, fatigue, hardness.

\section{INTRODUCTION}

Electroless-Nickel (EN) coatings have wide industrial applications owing to their excellent mechanical, physical, electrical, corrosion and wear resistance properties. Other outstanding characteristics of EN coatings include the ability to be applied to a variety of substrate materials and the ability to be plated uniformly on intricate part geometries. The phosphorus content of deposit defines the physical, mechanical and corrosion resistance properties of the coating $[1,2]$. There are three types of EN coatings available based on the weight percentage of phosphorus: (i) low phosphorus ( 2 to $5 \%$ ), (ii) medium phosphorus (6 to 9\%) and (iii) high phosphorus (10 to 13\%). Based on the presence of phosphorus content the structure may be microcrystalline, amorphous or a combination of both $[3,4]$

EN coatings generally have a high hardness, which increases considerably on heat treatment. There are three major parameters which affect the hardness of these coatings namely, phosphorus content, time and temperature of the applied post heat treatment $[5,6]$. It has been found that increasing the phosphorus content of the deposit lowers the hardness of the coating [7].

Further, EN coatings cause a significant reduction in the fatigue properties of steel substrate. The magnitude depends upon composition, heat treatment and coating thickness. Other studies show that the reduction of fatigue strength ranges between 10-50 \% [8,9]. Using an ultrasonic agitation system, the fatigue properties of EN coatings can be significantly improved [10].
One of the unique characteristics of EN coatings is superior wear resistance. Wear resistance depends on the phosphorus content and the type of post heat treatment applied.

In EN coatings, the corrosion resistance depends on porosity. Open pores on EN coatings lead to severe galvanic corrosion [11]. Therefore, a minimum thickness of $25 \mu \mathrm{m}$ was recommended with the least amount of pores and the highest corrosion and wear resistance [12].

In the present study, a medium phosphorus $\mathrm{Ni}-\mathrm{P}$ was coated on mild steel. The mechanical and corrosion properties and wear behaviour was studied.

\section{EXPERIMENTAL PROCEDURE}

\subsection{Electroless Bath Preparations}

To prepare a bath, an acrylic sheet material was selected which is non reactive to chemicals. A rectangular tank of 5 liter capacity bath was fabricated from this sheet. The $\mathrm{pH}$ value was maintained in the range of 4.8 to 5.2 for proper plating to take place. During the plating process, the $\mathrm{pH}$ of the system continuously decreases due to hydrogen evolution. It is monitored continuously using a $\mathrm{pH}$ meter. By using a suitable flow control aerator, the bath was agitated to maintain the uniformity of the solution and to prevent any localized temperature spikes. The bath temperature was maintained between $80{ }^{\circ} \mathrm{C}$ to $90{ }^{\circ} \mathrm{C}$ by using suitable heater with temperature controlling device [5]. 


\subsection{Surface Preparation}

Before the coating process, the surface to be coated was subjected to the following treatments as shown in Table 1.

Table - 1: Surface Treatment Processes

\begin{tabular}{|c|l|}
\hline S. No. & \multicolumn{1}{|c|}{ Treatment } \\
\hline 1 & $\begin{array}{l}\text { Kerosene cleaning at room temperature for } 2 \\
\text { minutes }\end{array}$ \\
\hline 2 & Rinsing with de-ionized water for 2 minutes \\
\hline 3 & Washing using detergent \\
\hline 4 & Rinsing with de-ionized water \\
\hline 5 & $\begin{array}{l}\text { Ultrasonic cleaning in acetone at } 60^{\circ} \mathrm{C} \text { for } 30 \\
\text { minutes }\end{array}$ \\
\hline 6 & Rinsing with de-ionized water \\
\hline 7 & Alkaline cleaning using $0.5 \mathrm{~N} \mathrm{NaOH}$ \\
\hline 8 & Rinsing with de-ionized water \\
\hline 9 & $\begin{array}{l}\text { Acid pickling using } 1: 1 \mathrm{HCl} \text { at } 60^{\circ} \mathrm{C} \text { for } 5 \\
\text { minutes }\end{array}$ \\
\hline 10 & Rinsing with hot de-ionized water for 2 minutes \\
\hline
\end{tabular}

\subsection{Plating Process}

The acrylic bath was filled with solution containing the following components as shown in Table 2 . The bath temperature was maintained at $85^{\circ} \mathrm{C}$. The prepared specimens were immersed in the bath with suitable hanger. The reaction between the substrate and the solution takes place indicating brisk effervescence. In order to maintain the $\mathrm{pH}$ of the bath, diluted ammonia was added periodically. Addition of the plating solution to the bath was done as and when required to compensate for evaporation during the total process duration of three hours.

Table - 2: Chemical Components of the Bath

\begin{tabular}{|l|l|c|}
\hline \multicolumn{1}{|c|}{ Component } & \multicolumn{1}{c|}{ Function } & Quantity \\
\hline Nickel Sulphate & Source of Metal Ion & $35 \mathrm{~g} / \mathrm{l}$ \\
\hline Sodium Hypophosphite & Reducing Agent & $30 \mathrm{~g} / \mathrm{l}$ \\
\hline Sodium Citrate & Complexant & $15 \mathrm{~g} / \mathrm{l}$ \\
\hline Distilled Water & Solvent & 11 \\
\hline
\end{tabular}

\subsection{Heat Treatment Process}

After the plating process, the specimens were subjected to heat treatment process in order to increase the mechanical and tribological properties. The various parameters used in the heat treatment process are given in Table 3. Inert atmosphere was used during the process.

Table - 3: Heat Treatment Parameters

\begin{tabular}{|c|c|c|c|}
\hline Temperature $\left({ }^{\mathbf{0}} \mathbf{C}\right)$ & \multicolumn{3}{|c|}{ Time (min.) } \\
\hline 300 & 30 & 60 & 90 \\
\hline 400 & 30 & 60 & 90 \\
\hline 500 & 30 & 60 & 90 \\
\hline
\end{tabular}

\subsection{Surface Roughness}

The surface roughness values were measured before and after the plating process, using Mitutoyo surface roughness tester (Model: ST 301). A specimen of size $20 \mathrm{~mm} \times 5 \mathrm{~mm}$ was used for this test. The detector was made to traverse over the specimen and the surface roughness value $\left(R_{a}\right)$ was taken directly from the display.

\subsection{Hardness Test}

The Vickers micro-hardness test was performed using Mitutoyo micro-hardness tester (Model: MVK-H11). Five readings were taken at various positions and the average value was calculated.

\subsection{Fatigue Test}

The fatigue test was performed using a fatigue tester (Make: Fine Testing Machines; Model: FIG-8) which has a maximum capacity of $225 \mathrm{~kg}-\mathrm{cm}$. Specimens were machined according to the machine standards. The test was performed on plain mild steel, plated and heat treated specimens. The speed of the machine was set at $4200 \mathrm{rpm}$. The value of the moment to be applied was selected after conducting series of tests over various specimens. Consecutively, a moment of $200 \mathrm{~kg}-\mathrm{cm}$ (Stress $=400 \mathrm{MPa}$ ) was applied on the specimen and the number of cycles that the specimen withstood before failing was noted down.

\subsection{Corrosion Test}

Corrosion test was conducted using weight loss method. The specimens were placed in various corrosive environments and the weight loss was noted every 24 hours. The corrosive environments selected were $1 \mathrm{~N} \mathrm{NaOH}, 0.1 \mathrm{~N} \mathrm{HCl}, 3.5 \%$ $\mathrm{NaCl}$. The specimens were weighed using an electronic balance and immersed in these different media. After 24 hours, specimens were weighed and the values noted down. The same procedure was repeated for the next four days and the weight loss of the specimens in each medium was obtained by finding the difference between the final and the initial value.

\subsection{Wear Test}

The wear test was conducted using pin-on-disc wear tester. The specimens were prepared as per ASTM (G99-04a) standard. The experiment was carried out in normal atmosphere. The test parameters are shown in Table 4. The test was performed on: (a) plain MS (b) plated MS and (c) plated and heat treated MS. 
Table - 4: Wear Test Parameters

\begin{tabular}{|l|l|}
\hline Parameter & Test Value \\
\hline Load & $15 \mathrm{~N}$ \\
\hline Velocity & $1.5 \mathrm{~m} / \mathrm{s}$ \\
\hline Speed & $320 \mathrm{rpm}$ \\
\hline Time & $1800 \mathrm{~s}$ \\
\hline Track Radius & $30 \mathrm{~mm}$ \\
\hline
\end{tabular}

\section{RESULTS AND DISCUSSION}

\subsection{Surface Roughness}

Figure 1 shows the roughness values of plated and unplated specimens. It was found that unplated specimens have large variation in roughness when compared to plated specimens. The unevenness present in the unplated specimens was corrected during the plating process. Hence, it may be concluded that plating process can improve the surface quality of the substrate.

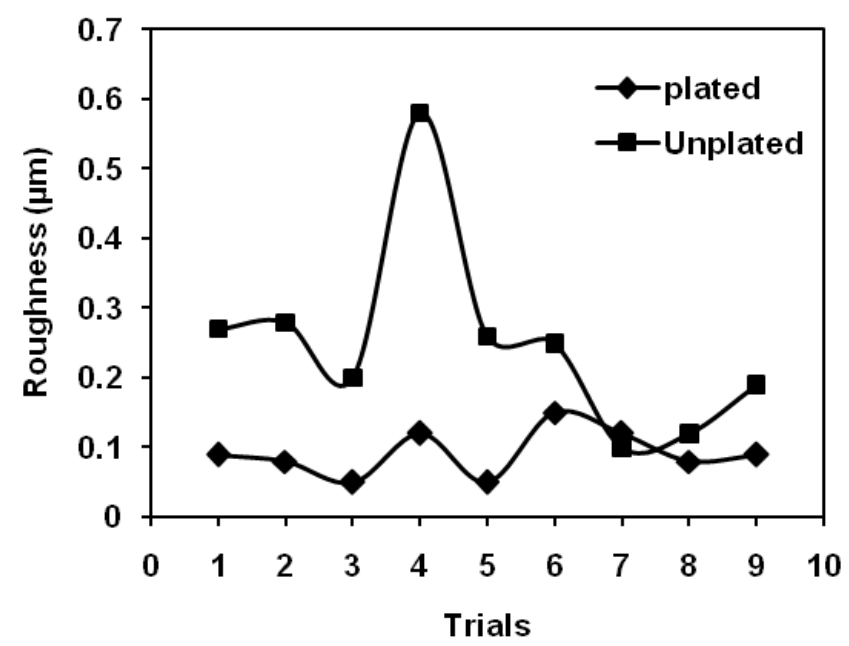

Fig-1: Surface Roughness of Plated and Unplated Specimens

\subsection{Hardness Test}

Figure 2 shows the micro-hardness of the specimens with respect to time when it was aged at various temperatures. The hardness of the plain MS was found to be $270 \mathrm{HV}$. For the plated specimen the hardness was increased to $545 \mathrm{HV}$. This shows that the nickel coating increases the hardness of the substrate at surface level. The plated specimens were aged for three different temperatures such as $300{ }^{\circ} \mathrm{C}, 400{ }^{\circ} \mathrm{C}$ and 500 ${ }^{\circ} \mathrm{C}$. It was observed that at $300{ }^{\circ} \mathrm{C}$ the hardness of the specimen increases with respect to time, whereas at $400{ }^{\circ} \mathrm{C}$ and $500{ }^{\circ} \mathrm{C}$ the hardness started to decrease. This may be due to the formation of nickel phosphide precipitates. The decrease in hardness causes the dissolution of the nickel phosphide precipitates due to over aging. Temperature and time are the contributing factor for over aging.

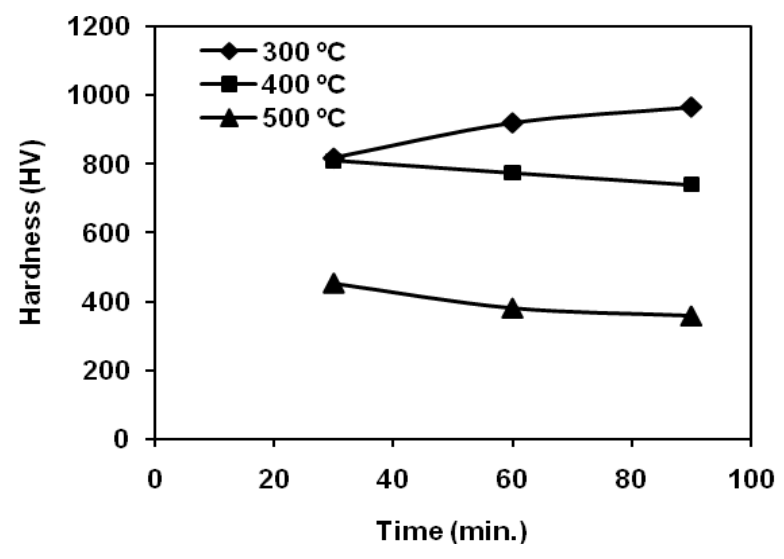

Fig-2: Hardness versus Time

\subsection{Fatigue Test}

The fatigue properties of the specimen treated in various conditions are shown in Table 5. The fatigue failure of the heat treated specimens occurs well in advance as compared to plated and plain MS specimens. This may be due to brittleness of the coating material. Hence, it may be concluded that the EN coatings followed by the heat treatment process decreases the fatigue strength of the substrate.

Table - 5: Comparison of Fatigue Strength

\begin{tabular}{|l|l|l|}
\hline \multirow{4}{*}{$\begin{array}{l}\text { Applied } \\
\text { Stress } \\
(400 \mathrm{MPa})\end{array}$} & Conditions & $\begin{array}{l}\text { No. of } \\
\text { Cycles to } \\
\text { Failure }\end{array}$ \\
\cline { 2 - 3 } & Plain MS & $1,15,000$ \\
\cline { 2 - 3 } & As Plated & 87,500 \\
\cline { 2 - 3 } & $\begin{array}{l}\text { Heat Treated } \\
\left(300^{\circ} \mathrm{C}-90 \text { min. }\right)\end{array}$ & 58,000 \\
\hline
\end{tabular}

\subsection{Corrosion Test}

The corrosive nature of plain MS, as plated and heat treated specimens were analyzed. Plain MS exhibits high corrosion in all mediums. This may be due to the continuous oxidation property of steel. In a basic medium like $\mathrm{NaOH}$, MS continuously emits electrons and forms ferric hydroxide as given in Equations 1 and 2.

$$
\begin{aligned}
& \mathrm{Fe} \rightarrow \mathrm{Fe}^{2+}+2 \mathrm{e}^{-}- \\
& \mathrm{Fe}^{2+}+\mathrm{OH}^{-} \rightarrow \mathrm{Fe}(\mathrm{OH})_{2}
\end{aligned}
$$

In acidic and marine media, chlorine continuously accepts electrons and forms metal chloride, which again undergoes hydrolysis to form metal hydroxide and $\mathrm{HCl}$ as shown in Equation 3. 


$$
\mathrm{Fe}^{2+} \mathrm{Cl}^{-}+\mathrm{H}_{2} \mathrm{O} \longrightarrow \mathrm{FeOH} \downarrow+\mathrm{H}^{+} \mathrm{Cl}^{-}
$$

The coated and heat treated specimens show excellent corrosion resistance in all media. This is due to the passive nature imparted to the substrate by the coating.

The weight loss of the specimens in each medium for plain MS and plated MS for different time periods are reported in Table 6 and 7.

Table - 6: Weight Loss Measurement of Plain MS Specimen

\begin{tabular}{|c|c|c|c|c|c|}
\hline \multirow[b]{2}{*}{ Conditions } & \multirow{2}{*}{$\begin{array}{c}\text { Weight } \\
\text { Before } \\
\text { Dipping } \\
\text { (g) }\end{array}$} & \multicolumn{4}{|c|}{ Weight After Dipping (g) } \\
\hline & & $\begin{array}{c}24 \\
\text { (hrs) }\end{array}$ & $\begin{array}{c}48 \\
\text { (hrs) }\end{array}$ & $\begin{array}{c}72 \\
\text { (hrs) }\end{array}$ & $\begin{array}{c}96 \\
\text { (hrs) }\end{array}$ \\
\hline $\begin{array}{c}0.1 \mathrm{~N} \\
\mathrm{NaOH}\end{array}$ & 8 & 4.8450 & 4.8441 & 4.8432 & 4.8420 \\
\hline $0.1 \mathrm{~N} \mathrm{HCl}$ & 4.8460 & 4.6420 & 4.3230 & 4.0980 & 3.9856 \\
\hline $\begin{array}{l}3.5 \% \\
\mathrm{NaCl}\end{array}$ & 5.0010 & 4.9850 & 4.9788 & 4.9669 & 4.9566 \\
\hline
\end{tabular}

Table - 7: Weight Loss Measurement of Plated Specimen

\begin{tabular}{|c|c|c|c|c|c|}
\hline \multirow[b]{2}{*}{ Conditions } & \multirow{2}{*}{$\begin{array}{l}\text { Weight } \\
\text { Before } \\
\text { Dipping } \\
\text { (g) }\end{array}$} & \multicolumn{4}{|c|}{ Weight After Dipping (g) } \\
\hline & & $\begin{array}{c}24 \\
\text { (hrs) }\end{array}$ & $\begin{array}{c}48 \\
\text { (hrs) }\end{array}$ & $\begin{array}{c}72 \\
(\mathrm{hrs})\end{array}$ & $\begin{array}{c}96 \\
\text { (hrs) }\end{array}$ \\
\hline $\begin{array}{c}0.1 \mathrm{~N} \\
\mathrm{NaOH}\end{array}$ & 4.8460 & 4.8458 & 4.8458 & 4.8456 & 4.8455 \\
\hline $0.1 \mathrm{~N} \mathrm{HCl}$ & 4.8469 & 4.7745 & 4.7346 & 4.7278 & 4.7253 \\
\hline $\begin{array}{l}3.5 \% \\
\mathrm{NaCl} \\
\end{array}$ & 5.0062 & 5.0042 & 5.0035 & 5.0030 & 5.0020 \\
\hline
\end{tabular}

\subsection{Wear Behaviour}

The wear behaviour was studied using pin-on-disc wear tester at constant load and time. Table 8 shows the variation of wear (height loss in $\mu \mathrm{m}$ ) and the coefficient of friction (COF) with respect to hardness and the condition of the specimen. As stated above, the hardness of the specimen increases with plated and heat treated conditions. It is to be noted from the table that the wear and $\mathrm{COF}$ values decreases as the hardness of the specimen increases. Hence, from the result it may be concluded that the plating and heat treatment processes are improving the wear properties of the substrate.

Table - 8: Hardness versus Wear Parameters

\begin{tabular}{|c|l|c|c|c|}
\hline Sl. No. & \multicolumn{1}{|c|}{ Condition } & $\begin{array}{c}\text { Hardness } \\
(\mathbf{H V})\end{array}$ & $\begin{array}{c}\text { Wear } \\
(\boldsymbol{\mu m})\end{array}$ & COF \\
\hline 1 & Plain MS & 270 & 220 & 0.555 \\
\hline 2 & Plated & 545 & 90 & 0.480 \\
\hline 3 & $\begin{array}{l}\text { Plated and Heat } \\
\text { Treated } \\
\left(300^{\circ} \mathrm{C}-90 \text { min. }\right)\end{array}$ & 965 & 60 & 0.250 \\
\hline
\end{tabular}

\section{CONCLUSIONS}

The effects of electroless coating and heat treatment process on mild steel specimens have been studied at different aging temperature and time. The following conclusions have been drawn on the present investigation:

- Plating process can improve the surface roughness of the substrate.

- Nickel coating increases the hardness of the substrate at surface level.

- The increase in hardness is due to the formation of nickel phosphide precipitates. The decrease in hardness causes the dissolution of the nickel phosphide precipitates due to over aging. Temperature and time are the contributing factor for over aging.

- Plating and heat treatment processes improve the wear properties of the substrate.

- The coated and heat treated specimens show excellent corrosion resistance in all media. This is due to the passive nature imparted to the substrate by the coating.

- EN coating followed by the heat treatment process decreases the fatigue strength of the substrate.

\section{REFERENCES}

[1] Park, S.H. and Lee, D.N. (1988), "A study on the microstructure and phase transformation of EN deposits" Journal of Materials Science, Vol.23, No.5, pp. 1643-1654.

[2] Goldstein, A.W. (1972), "Electron microscope study of nucleation and growth of electroless cobalt and nickel plating", Journal of the Electrochemical Society, Vol.119, pp.1614-1619.

[3] Barker, D, (1993),"Electroless deposition of metals", Transactions of the Institute of Metal Finishing, Vol.71, No.3, pp. 121-125

[4] Sang-Heon Hur, Jae-Han Jeong. and Dong Nyung Lee. (1990), "Microstructures and crystallization of Electroless Ni-P deposits", Journal of Materials Science, Vol.25, pp. 2573-2584

[5] Wolfgang Riedel. (1992), "Electroless Ni plating", ASM International, Vol.22, pp.68

[6] Baudrand, D.W. and Bengston, J. (1995),"Electroless plating processes developing technologies for Nickel, Palladium and Gold", Metal Finishing, pp.55-57.

[7] Duncan, R.N. (1996), "Metallurgical structure of EN deposit", Plating and Surface Finishing, Vol.83, pp.65.

[8] Safranck, W.H. (1959), "Nickel plating', ASTM Special Technical Publication, Vol.265, pp.41-49.

[9] Wu, Y., Zhang, Y. and Yao, M. (1995),"Effect of electroless nickel plating on fatigue strength of 30CrMoA steel", Plating and Surface Finishing, pp.8385

[10] Prasad, P.B., Shila, S., Vasudevan, R. and Seshadri, S.K. (1994), "Fatigue strength of nickel electro 
deposits prepared in ultrasonically agitated bath", Journal of Material Science Letters, Vol.13, pp.15-16.

[11] Leisner, P. and Benzon. (1997),"Porosity measurement of coatings", Transactions of the Institute of Metal Finishing, Vol.75, No.2, pp.88-92

[12] Deng, H. and Moller, P. (1993),"Effect of substrate surface morphology on the porosity of electroless nickel coatings", Transactions of the Institute of Metal Finishing, Vol.71, No.4, pp.142-148.

\section{BIOGRAPHIE}

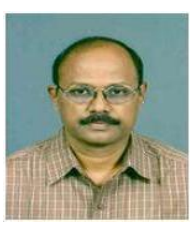

The author has completed his Bachelor's Degree in Mechanical Engineering and Master's Degree in Production Engineering. $\mathrm{He}$ has fourteen years of experience in industry and sixteen years in teaching. Further Engineering. he has completed Ph.D. in Materials 